\title{
Re search Paper: A Survey on the Relationship Between the Status of Occupational Health Management and Job Satisfaction Among Staff of Rehabilitation Centers in Tehran: A Cross-sectional Study
}

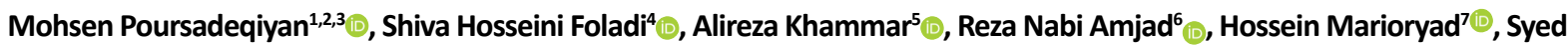
Nouredin Hosseini Ghosheh ${ }^{8}$, Monir AliMohammadi ${ }^{\oplus}$, ${ }^{*}$ Seyed Habiballah Kavari ${ }^{10}$ (1)

1. Health Sciences Research Center, Torbat Heydariyeh University of Medical Sciences, Torbat Heydariyeh, Iran.

2. Health in Emergency and Disaster Research center, University of Social Welfare and Rehabilitation Sciences, Tehran, Iran.

3. Department of Ergonomics, Pediatric Neurorehabilitation Research Center, University of Social Welfare and Rehabilitation Sciences, Tehran, Iran.

4. Student Research Committee, Department of Health Services Management, School of Management and Medical Informatics, Isfahan University of Medical Sciences, Isfahan, Iran.

5. Zabol Medicinal Plants Research Center, Department of Occupational Health, Faculty of Health, Zabol University of Medical Sciences, Zabol, Iran.

6. Non-Communicable Diseases Research Center, Alborz University of Medical Sciences, Karaj, Iran.

7. Social Determinants of Health Research Center, Yasuj University of Medical Sciences, Yasuj, Iran.

8. Department of Occupational Health Engineering, Behbahan University of Medical Sciences, Behbahan, Iran.

9. Health Management and Economics Research Center, Iran University of Medical Sciences, Tehran, Iran.

10. Department of Rehabilitation Management, University of Social Welfare and Rehabilitation Sciences, Tehran, Iran.

\begin{tabular}{|c|c|}
\hline $\begin{array}{l}\text { Use your device to tscan } \\
\text { and read the article online }\end{array}$ & ditation Poursadeqiyan M, Hosseini Foladi Sh, Khammar A, Nabi Amjad R, Marioryad H, Hosseini Ghosheh SN, et al. [A Survey on \\
\hline Giping & the Relationship Between the Status of Occupational Health Management and Job Satisfaction Among Staff of Rehabilitation Centers in \\
\hline 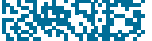 & Tehran: A Cross-Sectional Study (Persian)]. Archives of Rehabilitation. 2019; 20(3):242-255. http://dx.doi.org/10.32598/rj.20.3.242 \\
\hline 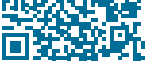 & doij" http://dx.doi.org/10.32598/rj.20.3.242 \\
\hline
\end{tabular}

\section{(i) (3)}

Received: 24 Feb 2019 Accepted: 13 Jul 2019 Available Online: 01 Oct 2019

\section{A BSTRACT}

Objective Paying more attention to human factors is undoubtedly one of the most important organizational principles. Job Satisfaction is one of the most important issues related to human resources in organizations and job dissatisfaction can decrease the productivity of the employees. In this regard, their occupational health is regarded as the science of workforce health in any organization. The purpose of this study was to investigate the status of Occupational Health Management and job satisfaction and the relationship between these two factors in the staff of rehabilitation centers in Tehran.

Materials \& Methods This descriptive correlation study was conducted on 1403 employees of 28 rehabilitation centers in Tehran during the second half of 2017. Sampling was done through the census. Research data were collected using a questionnaire consisting of two researcher-made questionnaires of occupational safety and health status and standard job satisfaction questionnaire. At first, the instrument used to assess occupational safety and health status for rehabilitation centers was developed and then, with the opinion of academic experts, the validity of the instrument was confirmed using the formal credibility and content validity index and the necessary corrections were made. In addition, 5-10 staff working in rehabilitation centers were asked about the content, clarity, and simplicity of the questionnaire terms. Content Validity Index (CVI) and Content Validity Coefficient (CVC) were 0.68, 0.83, 0.69, and 0.83 , respectively, for Occupational Health Management and job satisfaction. Instrument reliability was also assessed using the Cronbach's alpha coefficient, which was 0.872 . Finally, after verifying the validity and reliability of the instrument, a questionnaire was used to collect the research data. ShapiroWilk, Wilcoxon, and Spearman correlation tests were used to analyze the findings. Data analysis using Version 22.0. Armonk; NY: IBM Corp; SPSS V. 20.

Results The participants in this study included 657(46.8\%) male and 746(53.2\%) women. The results showed that the average score of Occupational Health Management variables and its sub-scales was

\section{* Corresponding Author:}

Seyed Habibollah Kovari, PhD.

Address: Department of Rehabilitation Management, University of Social Welfare and Rehabilitation Sciences, Tehran, Iran

Tel: +98 (21) 22180132

E-Mail: kavarih@gmail.com 
Keywords:

Occupational health management, Job satisfaction, Rehabilitation centers higher than the mean Likert scale. Job satisfaction variables and its subscales, other than the pay-asyou-go variable, were higher than the mean Likert score. The variables in "Occupational Health Management", "Public Safety", "Fire Extinguishment and Crisis", and "Ergonomics and Psychological Factors" were $0.65,0.57,0.60$, and 0.79 , respectively. Job satisfaction variables for job satisfaction, job, supervisor, coworker, and employee promotion were respectively $0.09 \%, 0.4 \%, 0.25 \%, 0.6 \%$, and $0.83 \%$ of the obtained variable. The regression coefficient between the two variables of Occupational Health Management and job satisfaction was 0.267 .

Conclusion According to the evaluation of the prepared and completed questionnaires, the results of this study showed that the level of job satisfaction and occupational health management in the studied centers is relatively favorable. Also, the results of this study confirmed that there was a significant positive correlation between the Occupational Health Management and the staff's job satisfaction working in rehabilitation centers $(P<0.001)$. It was argued that implementation of programs the extent to which occupational safety and health management system such as HSE in rehabilitation centers can affect the employee's job satisfaction. Therefore, it is necessary to provide more job satisfaction to the personnel of the centers by planning and following the necessary improvements to improve the level of health and safety of the occupational health centers. This will be important in the quality of the provided services. 
This Page Intentionally Left Blank 


\title{
بررسى رابطه وضعيت مديريت بهداشت حرفهاى و رضايت شغلى كاركنان مراكز توانبخشى شهر تهران: يكى مطالعه مقطعى روفيت مديريت
}

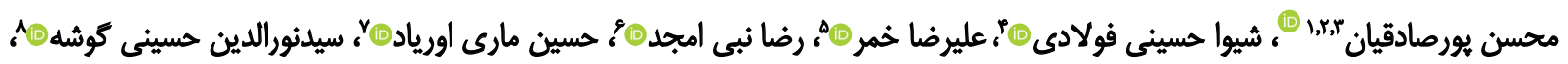

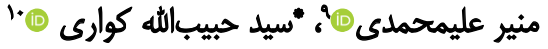

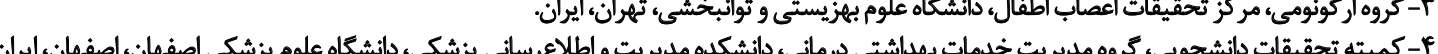

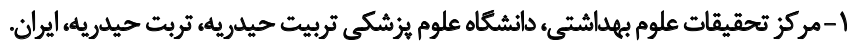

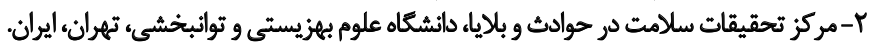

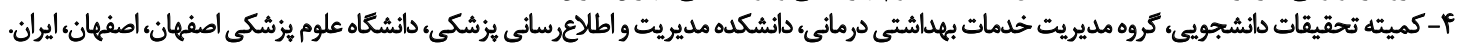

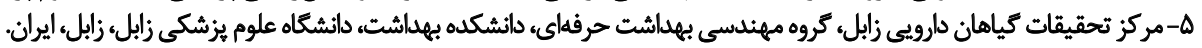

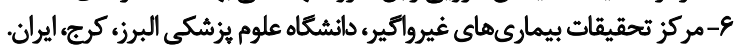

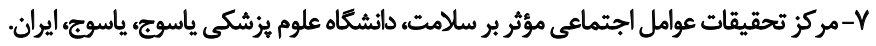

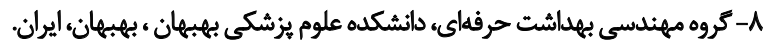

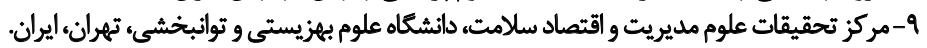

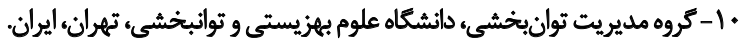

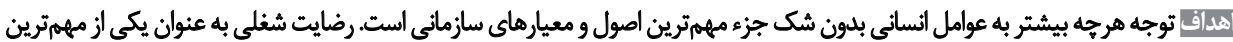

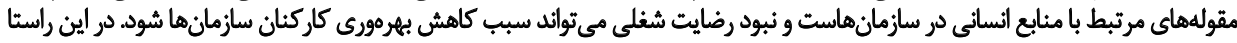

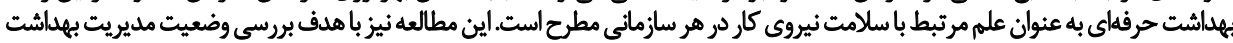

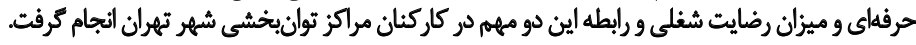

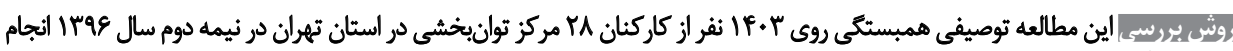

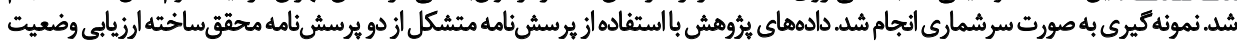

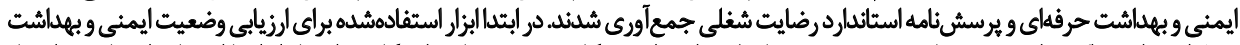

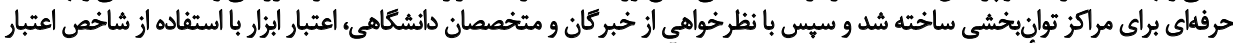

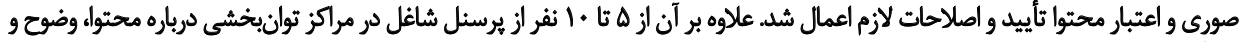

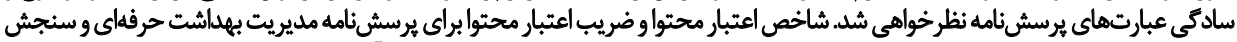

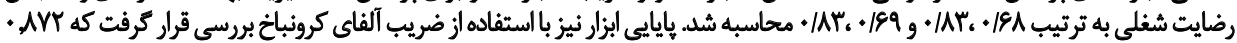

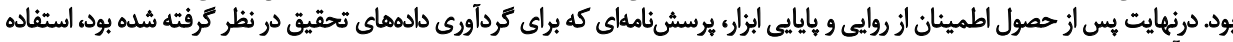

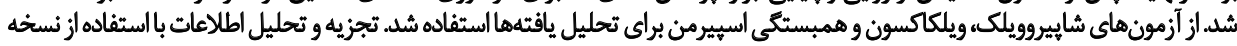

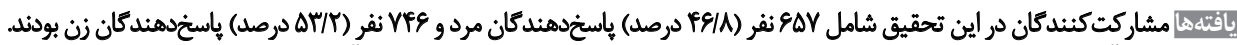

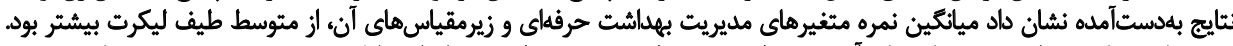

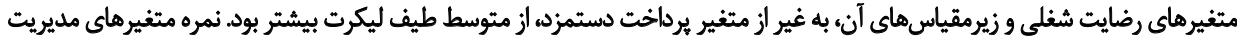

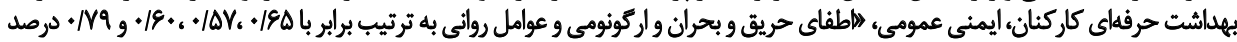

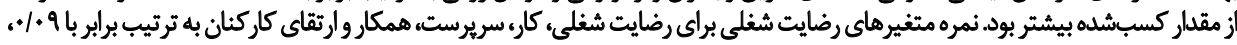

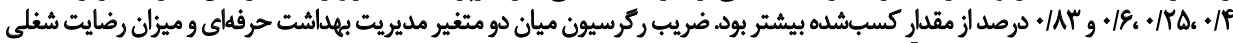

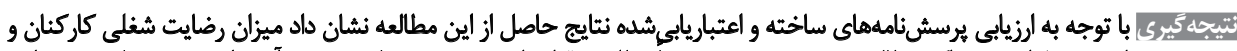

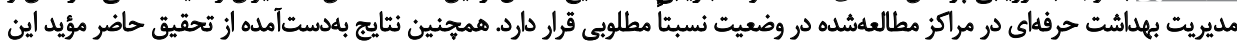

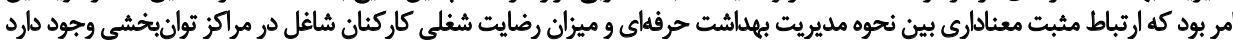

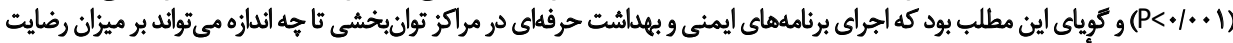

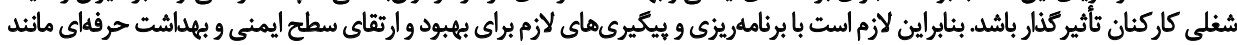

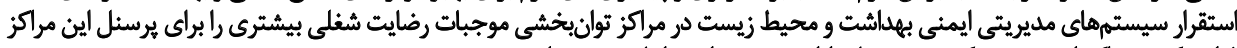

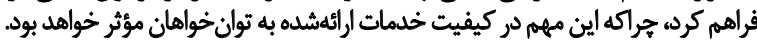

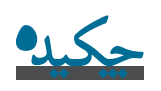

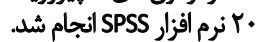

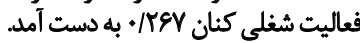

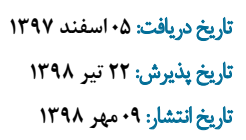

* فويسينده مسيئول:

دكتر سيدحبيبالله كوارى

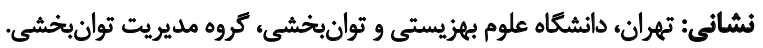

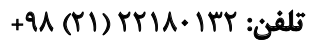
رايائامه: kavarih@gmail.com 
مديريت بهداشت حرفهاي علمى است كه از طريق شناسايى،

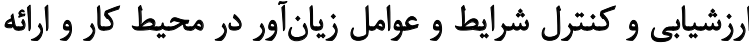

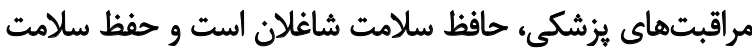

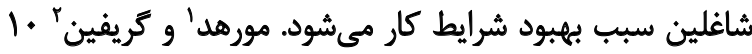

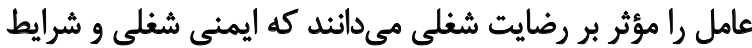

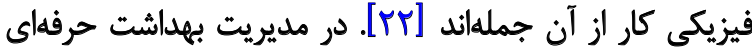

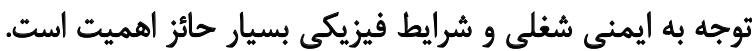

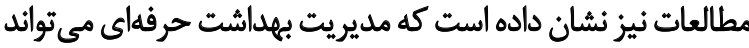

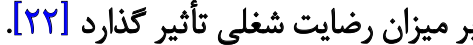

وجود بيمارىهاى حرفهاى و حوادث ناشى از كار به لحاظ إنائ

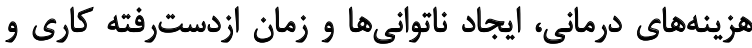

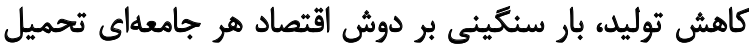

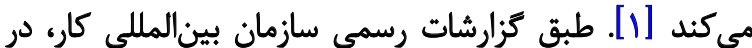

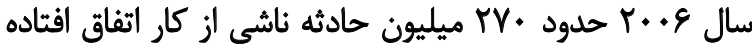

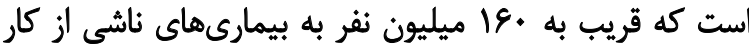

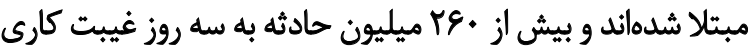

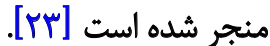

بنابراين در همه سازمانها بهويره سازمانهايى كه به جامئه

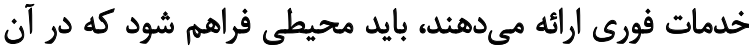

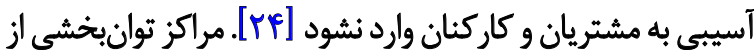

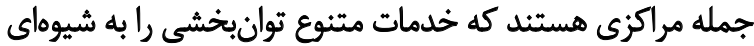

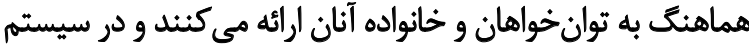

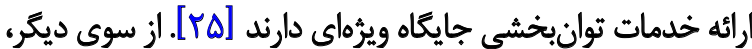

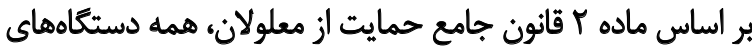

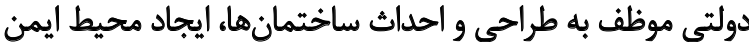

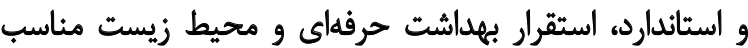

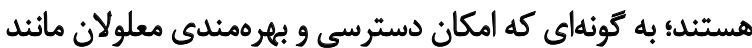

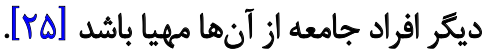

كاركنان توانبخشى افرادى هستند كه با مخاطبانى سروكار

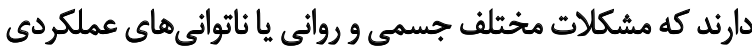

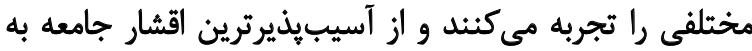

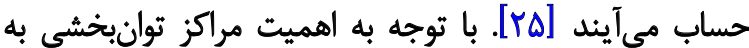

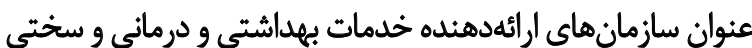

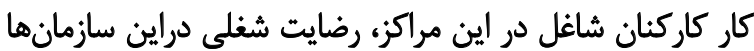

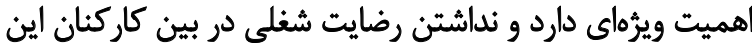

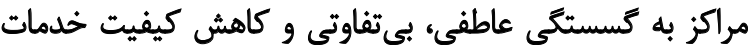

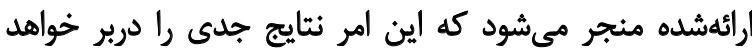

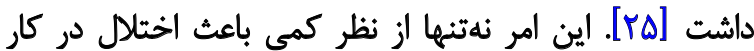

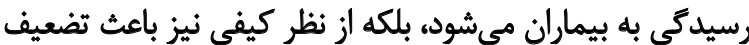

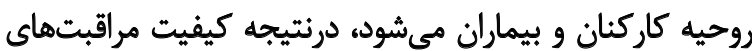

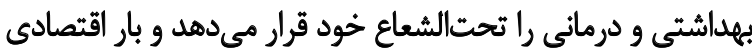

\section{Moorhead}

مقدمه

منابع انسانى سرمايههاى بنيادين سازمانها و منشأ هر گونه تحول

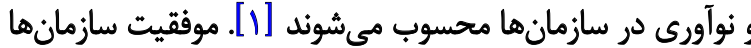

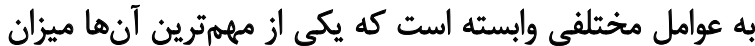

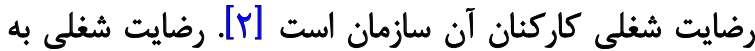

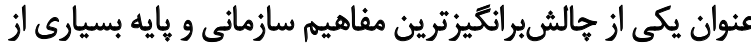

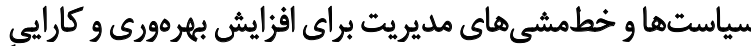

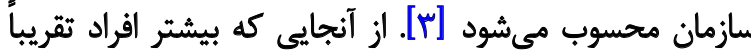

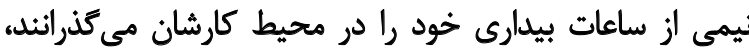

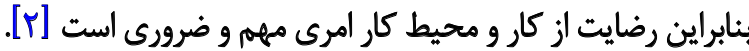
رضايت شغلى عبارت است از نوع نتحرش فرد نسبت به شغل

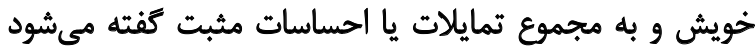

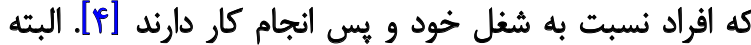

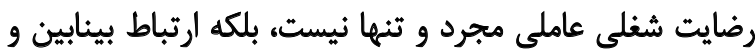

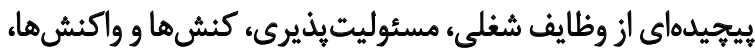

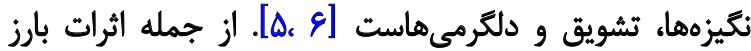

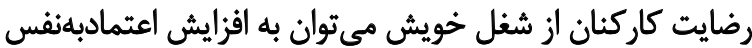

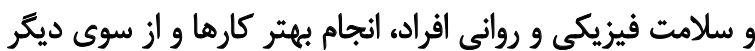

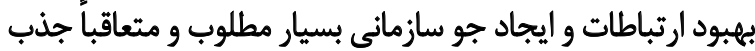

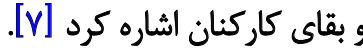

همجنين كاركنان با رضايت شغلى كم، سلامت روانى كمترى

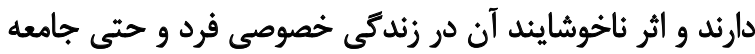

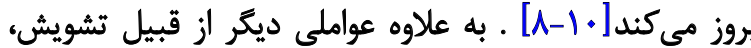

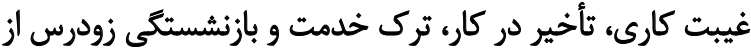

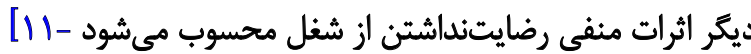

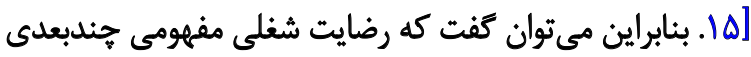

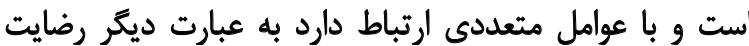

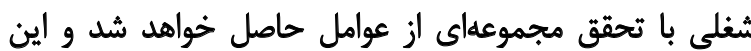

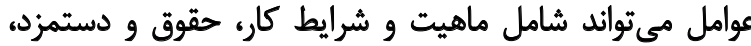

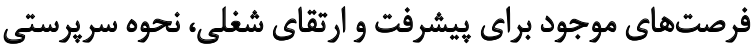

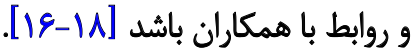

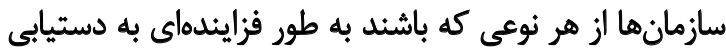

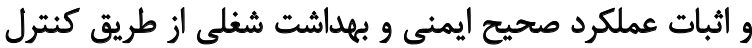

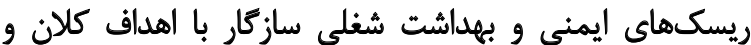

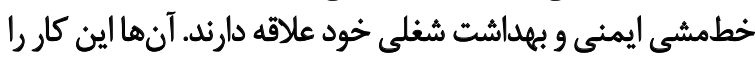

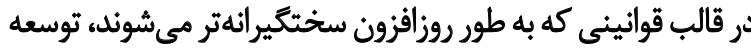

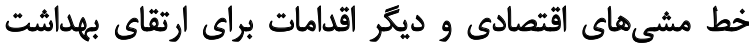

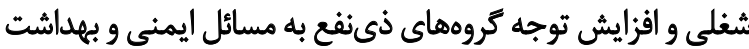

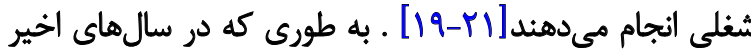

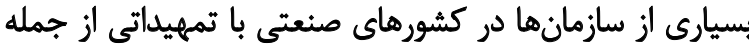

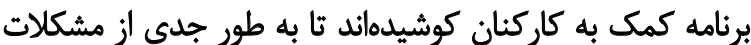

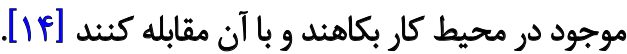




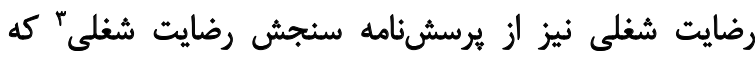

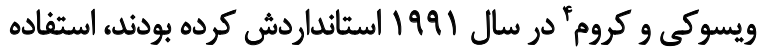

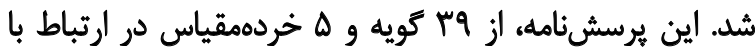

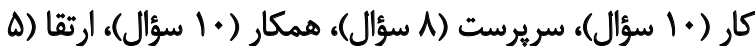

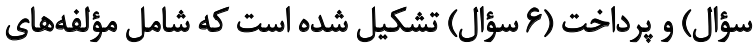
فعاليت شغلى، مديريت، فعاليتهاي كروهي، سيستم انظيزشى و

$$
\text { سيستم يرداختى بود. }
$$

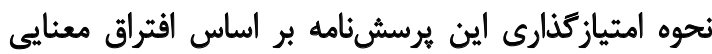

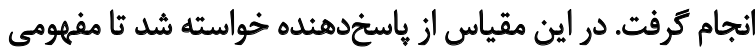

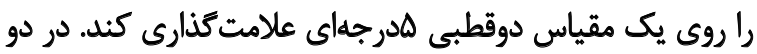

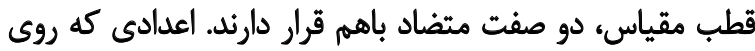

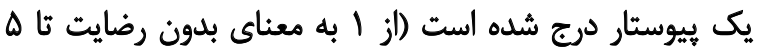

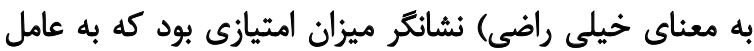

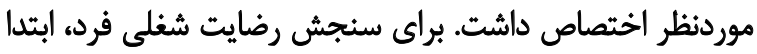

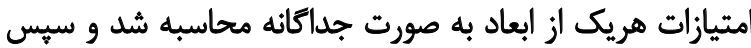

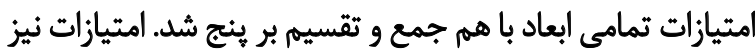

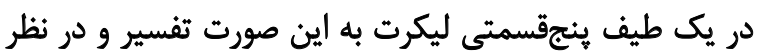

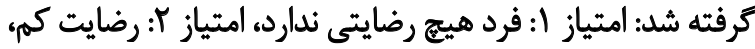

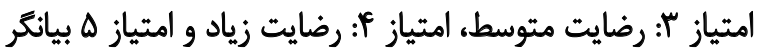

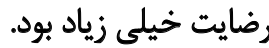

براى ارزيابى وضعيت مديريت بهداشت حرفهاي در مراكز

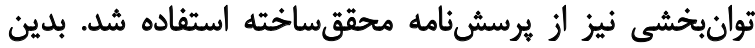

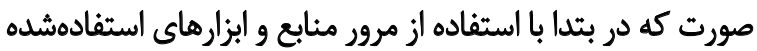

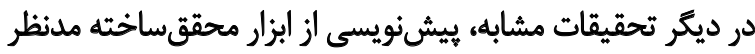

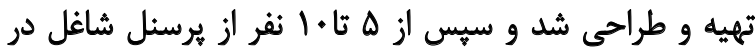

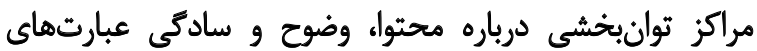
يرسشنامه نظرخواهى شد.

سيس با نظرخواهى از خبر كان و متخصصان دانشَاهى، اعتبار

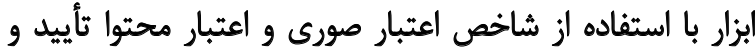

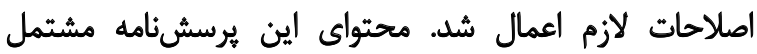

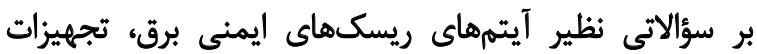

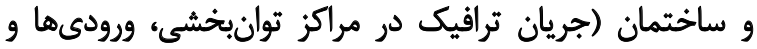

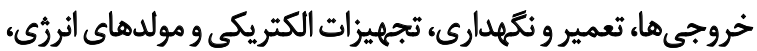

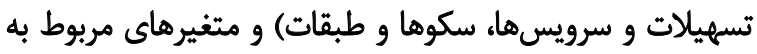

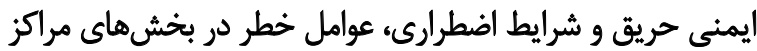

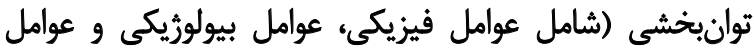

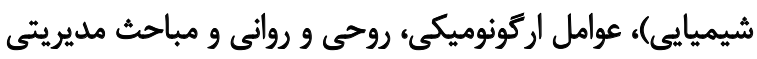

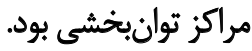

براى محاسبه اين شاخص از نظرات كارشناسان متخصص در

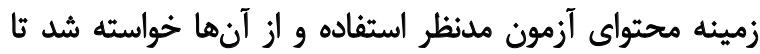

3. Job Descriptive Index (JDI)

4. Vysvky and Chrome
و مالى سنكينى را به سيستم سلامت وارد مي كند [عץ]. نظر به حساسيت و اهميت وظيفه و كاركرد مراكز توانبخشى

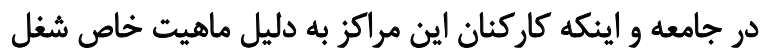

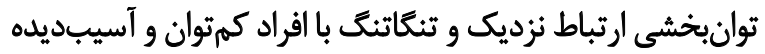

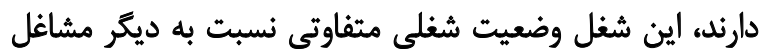

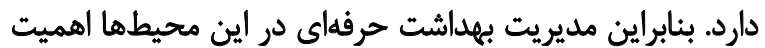

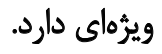

بر اساس مطالعات صورت كرفته حدود •ه درصد حوادث شغلى

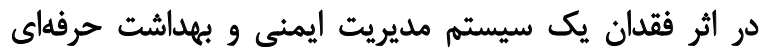

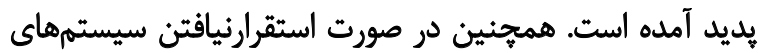

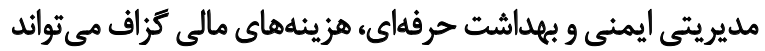

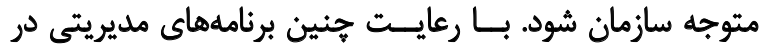

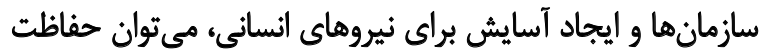

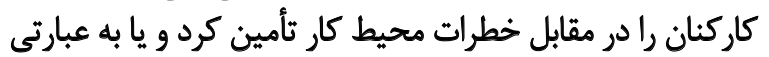

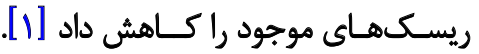
با اينكه تاكنون در سطح كشور مطالعات متعددى در زمينه

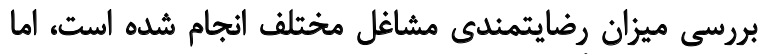

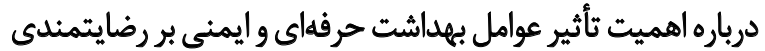
شغلى دركاركنان توانبخشى مطالعهاي انجام نكرفته است.

بنابراين مطالعه حاضر با هدف بررسى وضعيت مديريت ايمنى و

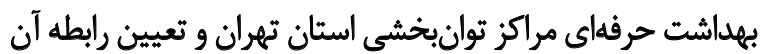

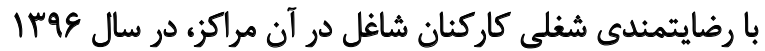

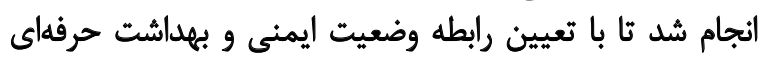

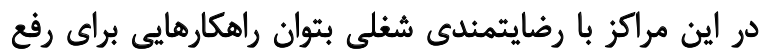

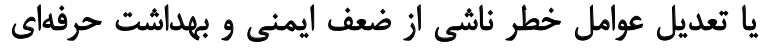

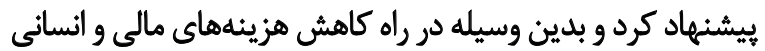

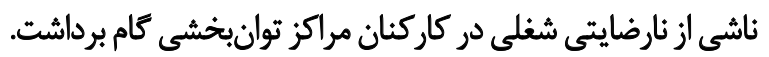

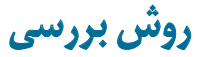

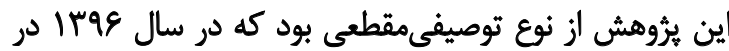

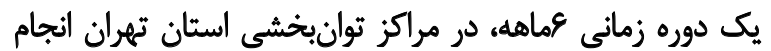

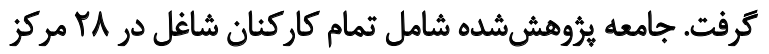

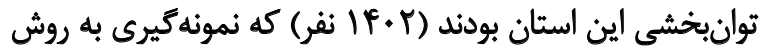

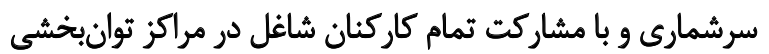

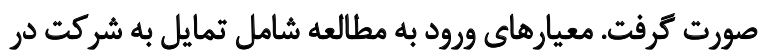

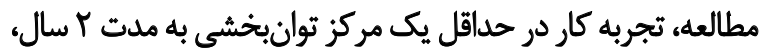

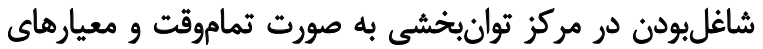

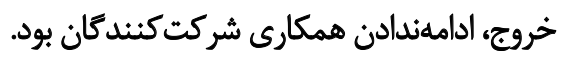

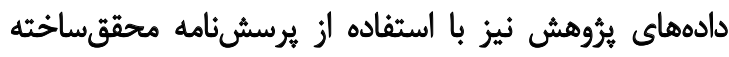

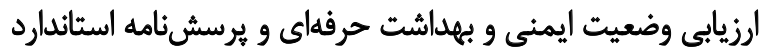

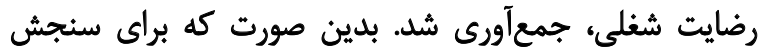


ياقتههها

آمار توصيفى ويرُخى هاى جمعيتشناختى نمونه تحقيق نشان

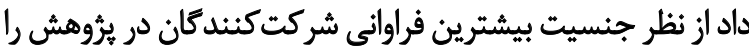

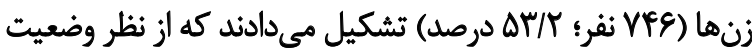

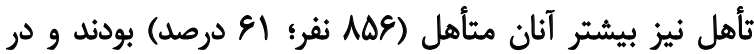

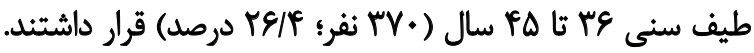

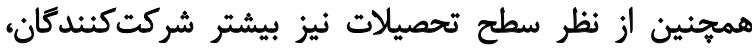

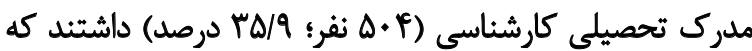

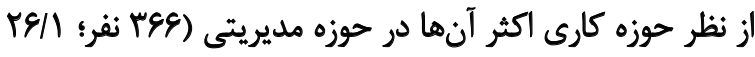

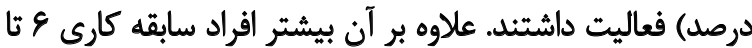

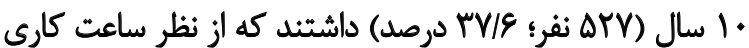

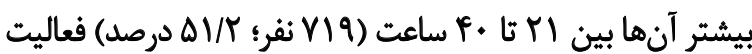
داشتئد.

بر اساس يافتههاى جدول شماره ا، متغيرهاى مديريت ايمنى

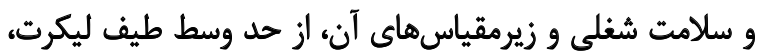

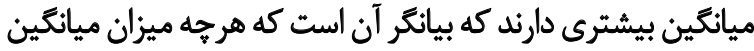

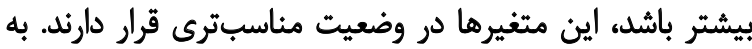

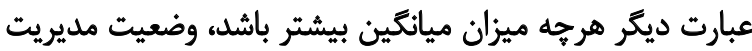

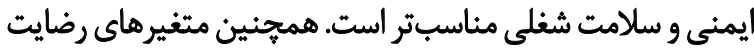

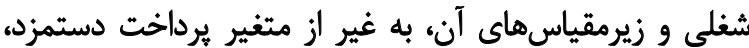

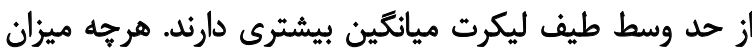

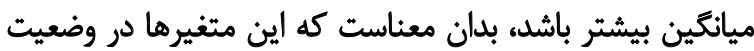

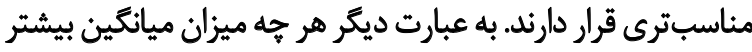
باشد، رضايت شغلى كاركنان بيشتر است

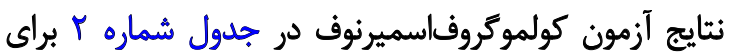

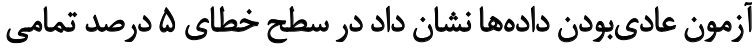

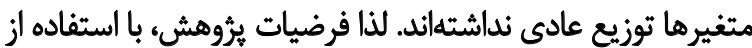

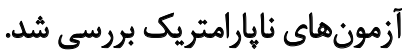

هريك از سؤالات را بر اساس طيف ينج كزينهاي ليكرت طبقهبندى

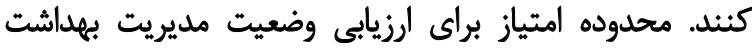

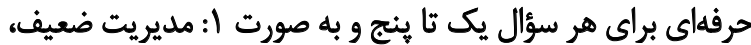

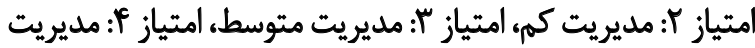

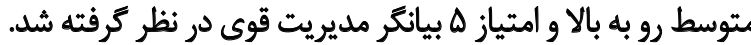

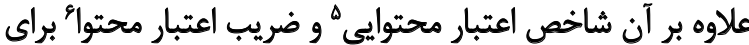

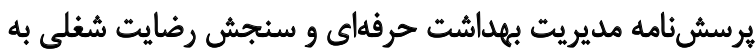

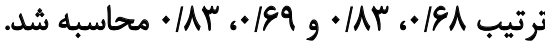

بايايى ابزار نيز با استفاده از ضريب آلفاى كرونباخ بررسى و

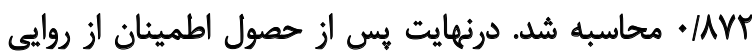

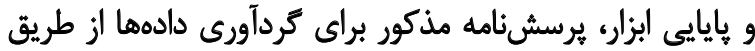

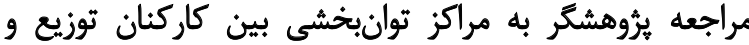

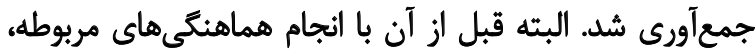

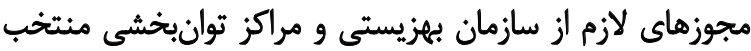

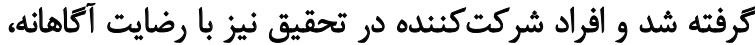

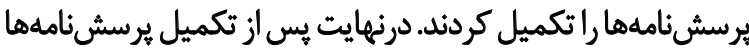

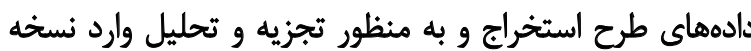

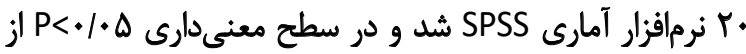

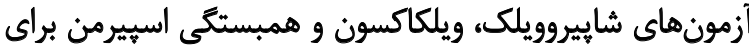

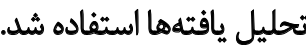

براى بررسى ويرُكى هاى جمعيتشناختى ياسخدهندكان نيز از

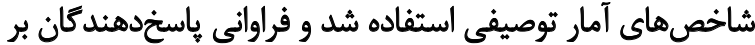
اساس جنسيت، تحصيلات، سابقه كارى، سن، تأهل تأهل، تعداد ساعات

$$
\text { كارى و حوزه كارى بررسى شد. تحديل }
$$

5. Content Validity Index (CVI)

6. Content Validity Ratio (CVR)

جدول (. توصيف متغيرهاي مديريت بهداشت حرفهاي و رضايت شغلى

\begin{tabular}{|c|c|c|c|}
\hline وارياتس & ميانكين & زيرمتغيرها & متغيرها \\
\hline$T / M$ & $\cdot / r \backslash \pm r / \& \Delta$ & هديريت بهيداشت حرقهاى & \multirow{4}{*}{ مديريت بهاشت حرقهاى } \\
\hline V/ar & . $/ F E \pm T / \Delta F$ & اليمنى عمومى & \\
\hline$T / F \Delta$ & . & اطفاى حريق و ايمنى & \\
\hline T/AP & - MADT/Ma & اركونوعى و عواهل روانى & \\
\hline$r / \Delta q$ & $. / M+ \pm T / M$ & رضايت شعلى كاركنان & \multirow{6}{*}{ رضايت شغلى كاركنان } \\
\hline$r \%$ & $\cdot R \cdot \pm r / r$ & كار - كار & \\
\hline$\% \%$ & $. / T \Delta \pm T / / \Lambda$ & سريرست & \\
\hline$r \%$ &.$|1 Y \pm r / 8|$ & ارتقا & \\
\hline $1 / 4$. & $.19 \Delta \pm \Psi / * \varphi$ & يرداخت دستمزد & \\
\hline $1 / *$ & $. / \Delta \Delta \pm Y / T \Delta$ & همكار & \\
\hline
\end{tabular}

توانغنننى 
جدول T. بررسى عادىبودن متغيرهاى ثيثروهش

\begin{tabular}{|c|c|c|c|}
\hline نتيجه أزمون & مقدار احتمال & مقدار ملاك نرماليتى & متغيرها \\
\hline غيرعادى & $<\bullet / \bullet+1$ & +/99४ & مديريت ايمنى و سلامث شغلى \\
\hline غيرعادى & $<\bullet \bullet \cdot+1$ & ./ave & ايمنى عمومى \\
\hline 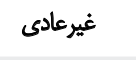 & $<\bullet / \bullet 1$ & ./9१४ & اطفا حريق و ايمنى \\
\hline غيرعادى & $<\bullet / \bullet+1$ & +/99\% & اركونومى و عوامل روانى \\
\hline غيرعادى & $<\bullet \bullet+1$ & $\cdot / A \cdot \varphi$ & رضايت شغلى كاركنان \\
\hline غيرعادى & $<\bullet \bullet \cdot 1$ &.$/ m$ & 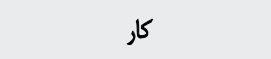 \\
\hline فيرعادى & $<\bullet / .+1$ & . $|8 T|$ & سريرست \\
\hline 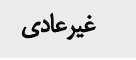 & $<\bullet \bullet \bullet 1$ &.$/ 9 \Delta T^{\circ}$ & همكار \\
\hline غيرعادى غ غ & $<\bullet / \bullet 1$ &.$/ 99$. & الرتقا \\
\hline ثيرعادى & $<\bullet / \bullet 1$ & 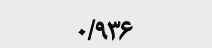 & يرداخت دستمزد \\
\hline
\end{tabular}

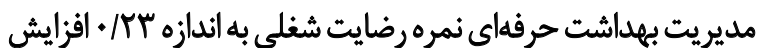

مىيابد كه اين افزايش از نظر آمارى معنادار بود (1 + • (P) يافتهماي جدول شماره ه هشان داد بُعد همكار بيشترين

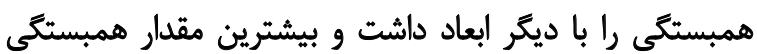

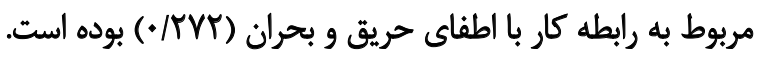

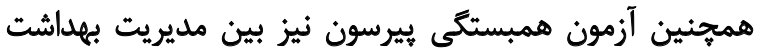
حرفهاى، ايمنى عمومى، اطفاى حريق و بحران و اركونومى و وعوامل

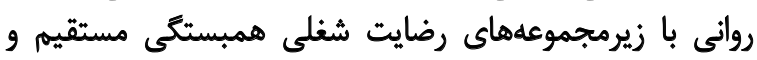

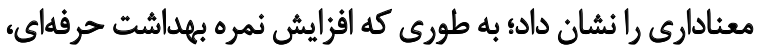

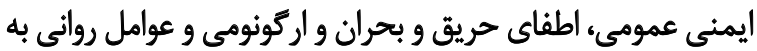

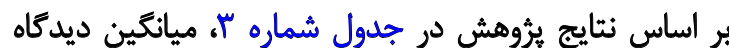

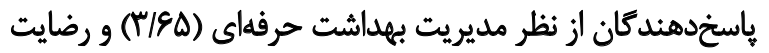

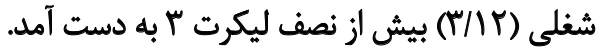

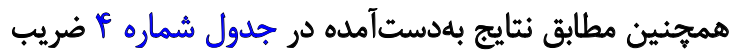

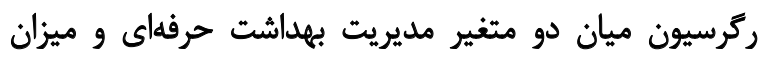

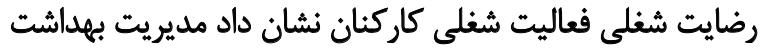

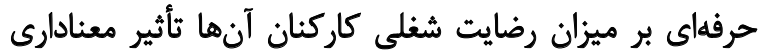
$(P<\cdot 1+1)$ ( 1 (

نتايج جدول شماره ب نيز نشان داد به ازاى يك واحد بهترشدن

جدول ب. تحليل توصيفى متغيرهاى تحقيق (r=1f)

\begin{tabular}{|c|c|c|c|c|c|}
\hline مقدار احتمال & مقدار ملاك & ميانه حاصلشده & ميانكين حاصلشده & ميانكين (ميانه) قابل كسب & متغير برؤش \\
\hline$<+1 \cdot .1$ & $\pi / R$ & r/ga & T/Fa & $r$ & مديريت بهناشت حرفهاى \\
\hline$<+1 \cdot, 1$ & TNET & $r / \Delta V$ & r/AS & r & ايمنى عمومى \\
\hline$<+1 *+1$ & rV/Aq & r/s & $r / R^{2}$ & r & اطفاى حريق و بحران \\
\hline$<\cdot / \cdot+1$ & 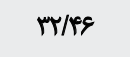 & $r / M$ & $r / A$ & r & اركونومى و عوامل روانى \\
\hline$<\cdot / . .1$ & WTq & $r / .9$ & $r / N r$ & $r$ & رضايت شغلى \\
\hline$<\cdot / \cdot+1$ & $\pi / \Delta)$ & $r / f$ & $m / f$ & $r$ & فعاليت شغلى \\
\hline$<+* \cdot 1$ & $r+/ . r$ & $\Gamma / T \Delta$ & T/TA & $r$ & مديريت \\
\hline$<+1++1$ & $\pi / \Delta M$ & r/s & $r / 91$ & $r$ & فعاليت كروهى \\
\hline.$\% H$ & 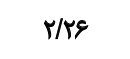 & $\Psi /+1$ & $r / . r$ & $r$ & سيستم الثكيزشى \\
\hline $.4 \pi$ & $-r q / \Delta r$ & $r / I V$ & $T / T \Delta$ & r & سيستم يرداختى \\
\hline
\end{tabular}


جدول ع. بررسى تأثير مديريت بهداشت حرفهاي بر ميزان رضايت شغلى كاركنان

\begin{tabular}{|c|c|c|c|c|c|}
\hline \multirow{2}{*}{ مقدار احتمال } & \multirow{2}{*}{ مقدار آماره تى } & \multirow{2}{*}{ ضريب استائداردشده } & \multicolumn{2}{|c|}{ ضريب غيراستاندارد } & \multirow{2}{*}{ مثغير مستقل } \\
\hline & & & افحراف استاندارد & مقدار & \\
\hline$<+1 *+1$ & $9 / \pi$ &.$/ T r Y$ & $.1 .5 q$ &.$/ \pi V$ & مديريت بهلائشت حرفهاى \\
\hline
\end{tabular}

جدول ه. بررسى همبستَى بين ابعاد مديريت بهداشت حرفهاى با رضايت شغلى

\begin{tabular}{|c|c|c|c|}
\hline مقدار احتمال & همبستئى & \multicolumn{2}{|c|}{ ارتباط بين متثيرها } \\
\hline$<* / *+1$ & - & رضايت شُغلى & \\
\hline$<+1 *+1$ & . Taf & كار & \\
\hline$<+1 \cdot+1$ &.$/ M$ & سريرست & مليريت بهداشت \\
\hline$<+1++1$ & 1.9\% & همكار & حرفهاي با \\
\hline$<+1++1$ & $+/+r$ & الرتقا & \\
\hline$<\cdot 1 \cdot .1$ &. $\mid 181$ & يرداخت دستمزد & \\
\hline$<\bullet / .+1$ &.$/ T H Y$ & رضايت شغلى & \\
\hline$<\bullet / . .1$ & $. / r \mid$ & كار & \\
\hline$<\bullet / . \bullet 1$ & - IIfF & سريرست & \\
\hline$<\cdot / *+1$ & $\cdot / 1 \cdot 1$ & همكار & 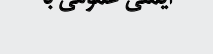 \\
\hline$<\bullet / . \bullet 1$ &.$/ 11 Y$ & ارتقا & \\
\hline$<* *+1$ & . IST & يرداخت دستمزد & \\
\hline$<+1++1$ & $+/ \pi / \Delta$ & رضايت شغلى & \\
\hline$<+1++1$ & $+/ r r$ & كار & \\
\hline$<+1 *+1$ & $+R+r$ & سريرست & \\
\hline$<\bullet / \bullet+1$ & $\cdot 11+1$ & همكار & 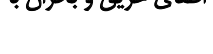 \\
\hline$<\cdot 1 \cdot+1$ & .1 .8 & الرتقا & \\
\hline$<* / * .1$ &.$/ 10$ & يرداخت دستمزد & \\
\hline$<\bullet / * \bullet$ & . & رضايت شغلى & \\
\hline$<* / *+1$ &.$/$ IA & كار & \\
\hline$<\bullet+\cdots 1$ &.$/ 1 Y a$ & سريرنست & 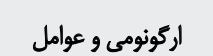 \\
\hline$<+1 *+1$ & $+11+4$ & همكار & \\
\hline$<+1++1$ & +1119 & الرتقا & \\
\hline$<+1 *+1$ &.$/ 18$ & برداخت دستمزد & \\
\hline
\end{tabular}


همجنين نتايج مطالعه نشان داد ميانكين نمره متغيرهاى

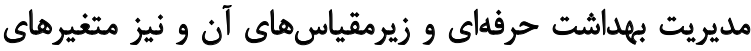

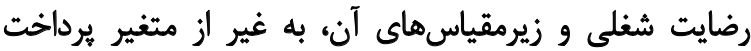

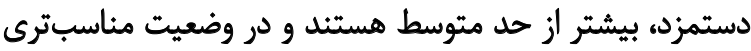

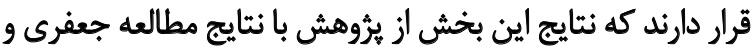

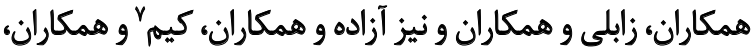

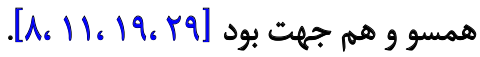

در توجيه اين بخش ار نتايج ميتوان كفت كه ايمنى بالاو و رئان

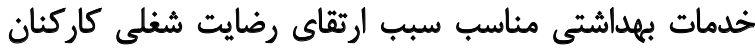

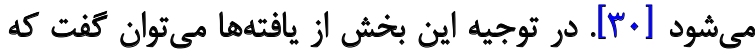

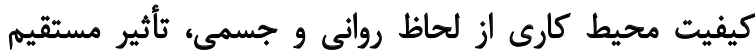

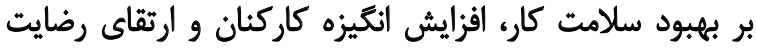

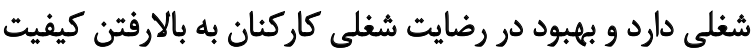

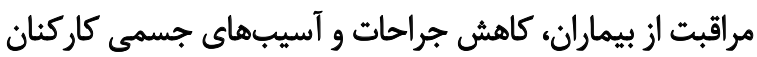

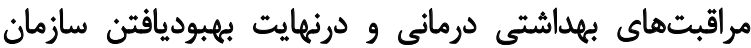

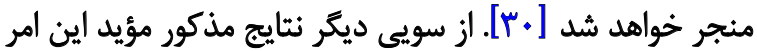

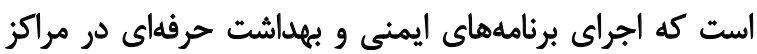

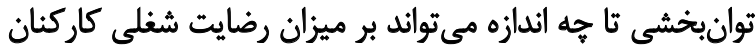

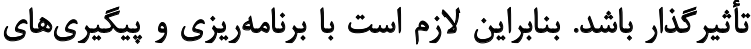

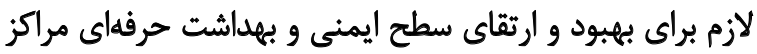

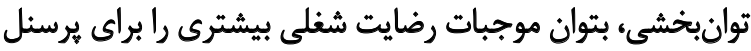

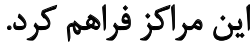

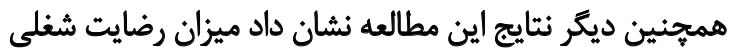

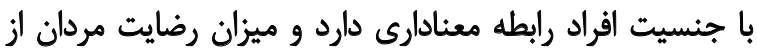

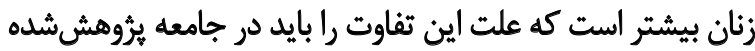

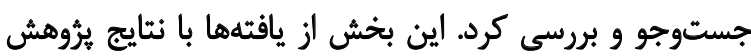
جعفرى و همكاران مطابقت داشت [11]

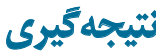

يكى از اهداف اين مطالعه طراحى جكليست ارزيابى مديريت

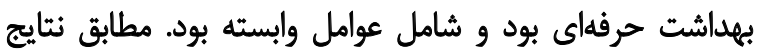

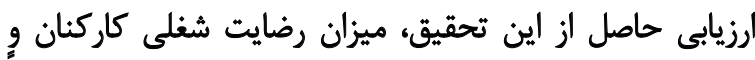
مديريت بهداشت حرفهاى در مراكز مطالعهشده در وضعيت نسبتا

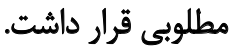

هميجنين نتايج بهدستآمده از تحقيق حاضر مؤيد اين امر بود

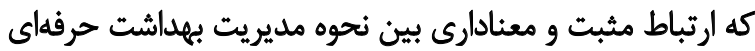

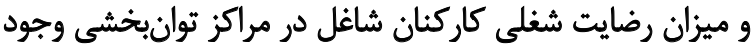

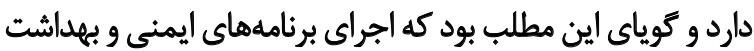

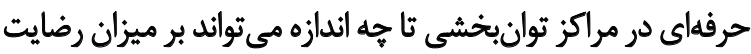

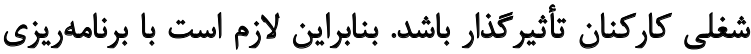

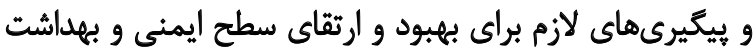

افزايش معنادار رضايت شغلى منجر شد (1 . P<> P>). همجنين يافتههاى جدول شماره ه نشان داد بين مديريت

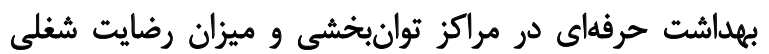

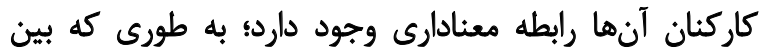

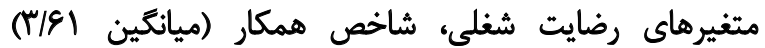

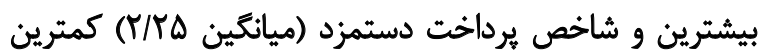

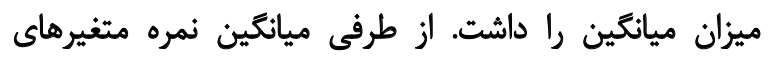

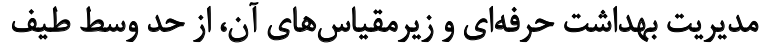
ليكرت نمره بيشترى داشتئد.

در متغيرهاى رضايت شغلى و زيرمقياس هاي آنه، به غير از متغير

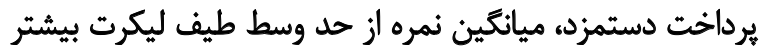

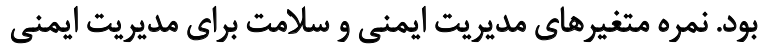

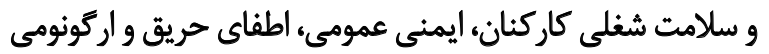

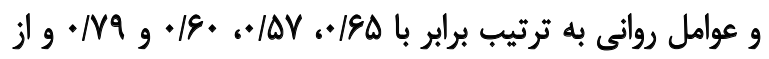

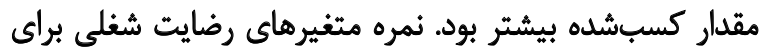

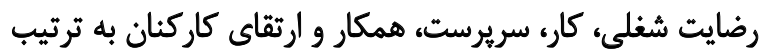

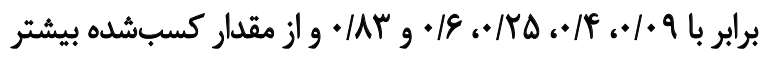

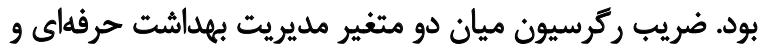

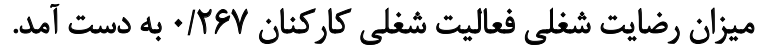

بحث

اين مطالعه با هدف بررسى رابطه وضعيت مديريت ايمنى و و

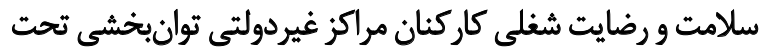

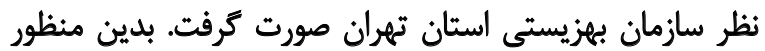

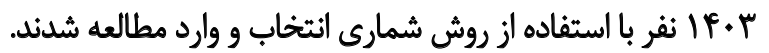

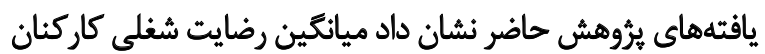
مان

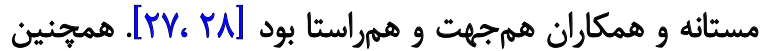

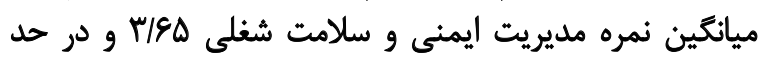

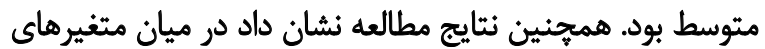

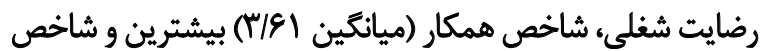

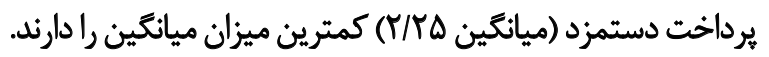
در مطالعه افشارى و همكاران بين متغيرهاى جمعيتشناختى و ورئي

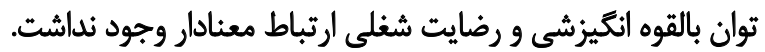

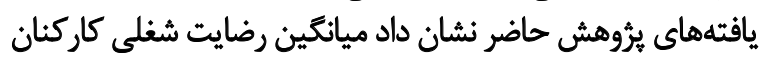

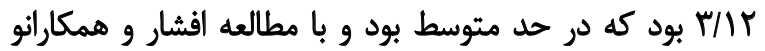

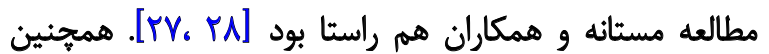

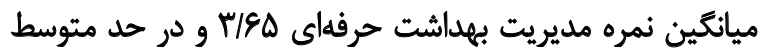

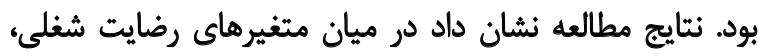

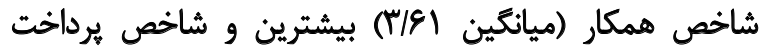

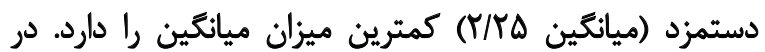

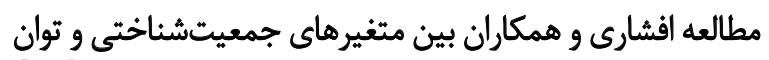

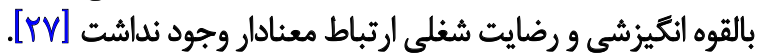




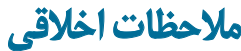 \\ ييروى أز اصول اخلاق ثئوهش}

اين مقاله بركَرفته از طرح يروهشى با كد طرح 1911 امصوب

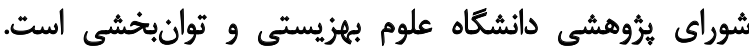

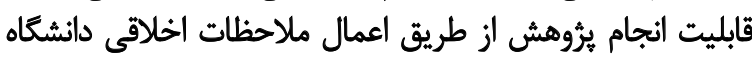

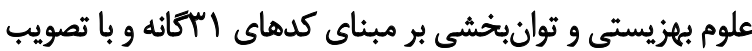
معاونت يُروهشى طبق شماره

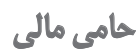

مقاله فوق مستخرج از طرحى با همين عنوان، در شوراى

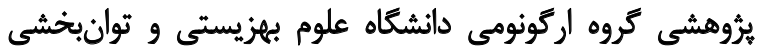

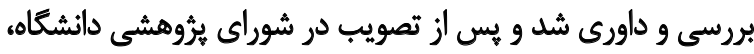

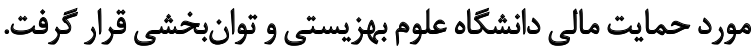

\section{مشاركت نويسئدكَّان}

كليه نويسندكان در انجام طرح و نيز نتارش مقاله همكارى

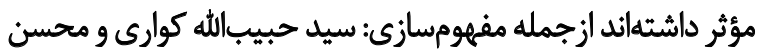

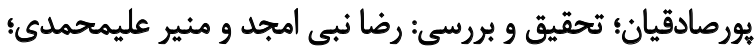

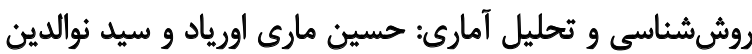

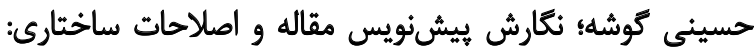

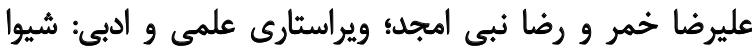

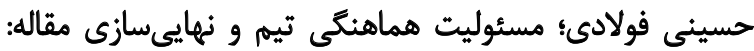

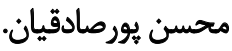

تمارض منأقع

بنابر اظهارات نويسندكان تعارض منافع وجود ندارد.

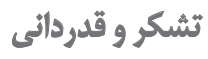

نويسندكان به رسم ادب و اخلاق از زحمات تمام استادان و

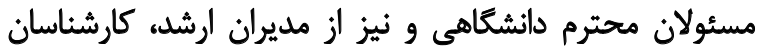

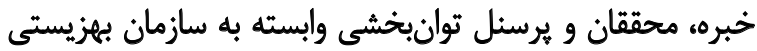

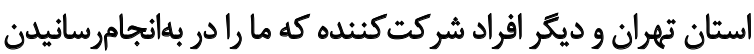
اين يثروهش يارى كردند، كمال تشكر و سياسكزارى را مئنمايند.
حرفهاي مراكز توانبخشى موجبات رضايت شغلى بيشترى را براى

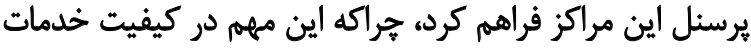

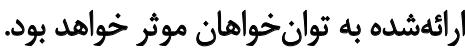

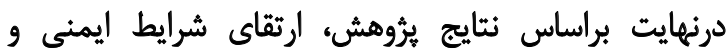

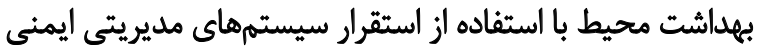

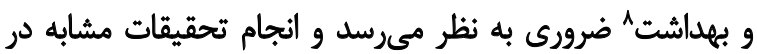

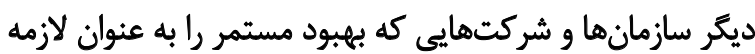

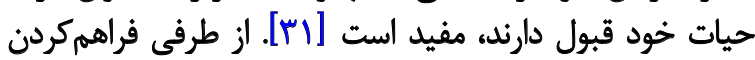

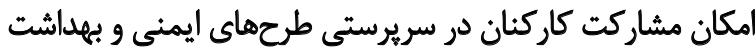

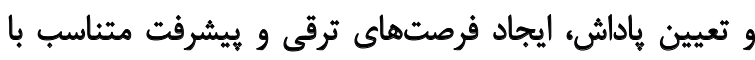

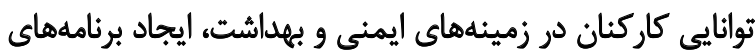

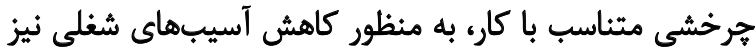

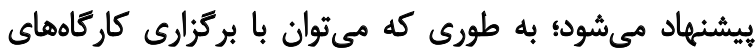

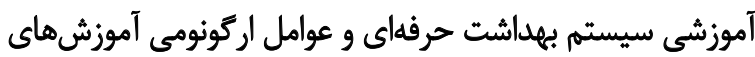
ل الازم رادر اين زمينه ارائه كرد.

از طرفى با توجه به تحقيقات انجامشده در كشورهاى ديكر،

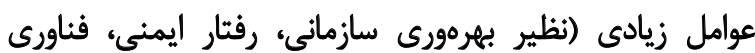

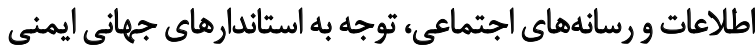

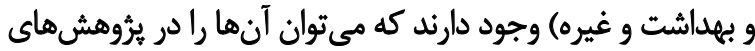

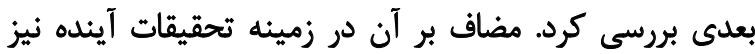

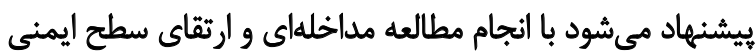

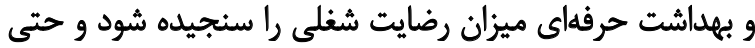

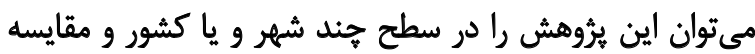
نتايج آنها به روش تركيبى كتّى و كيفى نيز انجام داد.

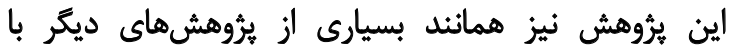

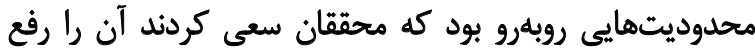

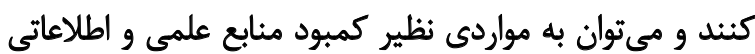

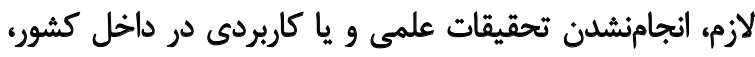

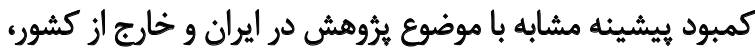

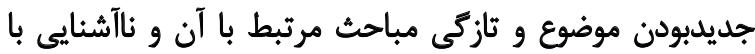

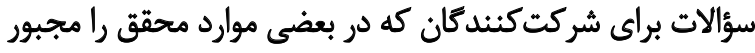

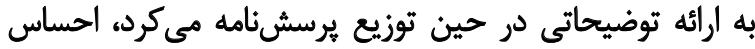

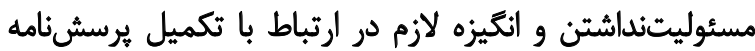

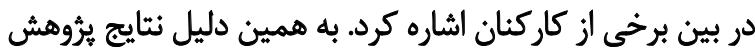

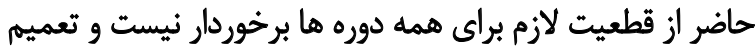

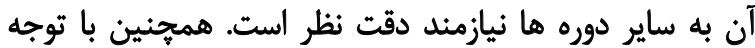

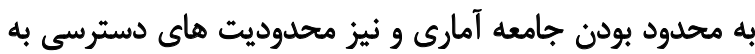

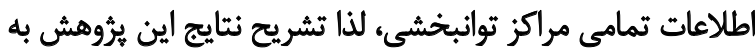

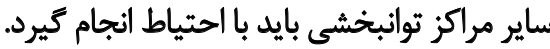




\section{References}

[1] Khandan M, Aligol MH, Shamsi M, PourSadeqiyan M, Biglari $\mathrm{H}$, Koohpaei A. Occupational health, safety, and ergonomics challenges and opportunities based on the organizational structure analysis: A case study in the selected manufacturing industries in Qom Province, Iran, 2015. Annals of Tropical Medicine and Public Health. 2017; 10(3):606-11.

[2] Moradi S, Farahnaki Z, Akbarzadeh A, Gharagozlou F, Pournajaf A, Abbasi AM, et al. Relationship between shift work and job satisfaction among nurses: A Cross-sectional study. International Journal of Hospital Research. 2014; 3(2):63-8.

[3] Abbasi M, Yazdani Rad S, Habibi P, Arabi S, Fallah Madvari R, Mehri A, et al. Relationship among noise exposure, sensitivity, and noise annoyance with job satisfaction and job stress in a textile industry. Noise \& Vibration Worldwide. 2019; 50(6):195-201 [DOI: 10.1177/0957456519853812]

[4] PourSadeqiyan M, Abbasi M, Mehri A, Hami M, Raei M, Ebrahimi MH. Relationship between job stress and anxiety, depression and job satisfaction in nurses in Iran. The Social Science. 2016; 11(9):2349-55.

[5] Karami J, Moradi A, Hatamian P. The effect of resilience, selfefficacy, and social support on job satisfaction among the employed, middle-aged and elderly. Iranian Journal of Ageing. 2017; 12(3):300-11. [DOI:10.21859/sija.12.3.300]

[6] Farajpour Khazai O, Pishyare E, Rassafani M, Bakhshi E, Poursadeqiyan $\mathrm{M}$. The relationship between areas of occupation and severity of depression, anxiety, and stress in Parkinson's disease (Persian)]. Archives of Rehabilitation. 2019; 20(2):190201.

[7] Azadeh A, Zarrin M. An intelligent framework for productivity assessment and analysis of human resource from resilience engineering, motivational factors, HSE and ergonomics perspectives. Safety Science. 2016; 89:55-71. [DOI:10.1016/j. ssci.2016.06.001]

[8] Kim Y, Park J, Park M. Creating a culture of prevention in occupational safety and health practice. Safety and Health at Work. 2016; 7(2):89-96. [DOI:10.1016/j.shaw.2016.02.002] [PMID] [PMCID]

[9] Molamohamadi Z, Ismail N. The relationship between occupational safety, health, and environment, and sustainable development: A review and critique. International Journal of Innovation, Management and Technology. 2014; 5(3):198202. [DOI:10.7763/IIIMT.2014.V5.513]

[10] Hauff S, Richter NF, Tressin T. Situational job characteristics and job satisfaction: The moderating role of national culture. International Business Review. 2015; 24(4):710-23. [DOI:10.1016/j.ibusrev.2015.01.003]

[11] Jafari M. [The relationship between job satisfaction and occupational safety and occupational health status of nurses in a hospital (Persian)]. Journal of Health and Safety at Work. 2012; 2(3):41-8.

[12] Malliarou M, Moustaka E, Kouvela T, Constantinidis TC, Sarafis P. Greek registered nurses' job satisfaction in relation to work-related stress: A study on army and civilian RNS. Global
Journal of Health Science. 2010; 2(1):44-59. [DOI:10.5539/ gjhs.v2n1p44]

[13] PourSadeqiyan M, Moghimian M, Amjad RN, Baneshi MM, Yari A, Noroozi M, et al. Effects on job stress on Iranian clinical nurses. Annals of Tropical Medicine and Public Health. 2017; 10(4):985-8. [DOI:10.4103/ATMPH.ATMPH_306_17]

[14] Pakjoo A, Mirza Ebrahim Tehrani M, Malmasi S. [Assessing the effectiveness of HSE management programs and its relationship with job satisfaction one of the vegetable oil production plant at the west of Tehran (Persian)]. Journal of Occupational Hygiene Engineering. 2017; 3(4):10-21. [DOI:10.21859/ johe-03042]

[15] Khammar A, Amjad RN, Rohani M, Yari A, Noroozi M, Poursadeghian $A$, et al. Survey of shift work disorders and occupational stress among nurses: A cross-sectional study. Ann Trop Med Public Health . 2017; 10(4):978-84

[16] Silla I, Navajas J, Koves GK. Organizational culture and a safetyconscious work environment: The mediating role of employee communication satisfaction. Journal of Safety Research. 2017; 61:121-7. [DOI:10.1016/j.jsr.2017.02.005] [PMID]

[17] Khammar A, Dalvand S, Hashemian AH, PourSadeqiyan M, Yarmohammadi S, Babakhani J, et al. Data for the prevalence of nurses' burnout in Iran (A meta-analysis dataset). Data in Brief. 2018; 20: 1779-86.

[18] Abbasi M, Farhang Dehghan S, Fallah Madvari R, Mehri A, Ebrahimi MH, PourSadeqiyan $\mathrm{M}$, et al. Interactive effect of background variables and workload parameters on the quality of life among nurses working in highly complex hospital units: A cross-sectional study. Journal of Clinical and Diagnostic Research. 2019; (13)1:LC8-13.

[19] Zaboli R, Tofighi s, Valipour F, Hasani M. [Effect of occupational health and safety management standards and environmental management on environmental factors and employees satisfaction at Milad industrial complex- before and after study (Persian)]. Journal of Nurse and Physician Within War. 2014; 25:30-4.

[20] Cheah WL, Giloi N, Chang CT, Lim JF. The perception, level of safety satisfaction and safety feedback on occupational safety and health management among hospital staff nurses in Sabah State Health Department. The Malaysian Journal of Medical Sciences. 2012; 19(3):57-63. [PMID] [PMCID]

[21] Serkalem SY, Haimanot GM, Ansha NA. Determinants of occupational injury in Kombolcha textile factory, north-east ethiopia. International Journal of Occupational and Environmental Medicine. 2014; 5(2):327-84. [PMID]

[22] Kolins Givan R. Seeing stars: Human resources performance indicators in the National Health Service. Personnel Review. 2005; 34(6):634-47. [DOI:10.1108/00483480510623439]

[23] Hämäläinen P, Takala J, Saarela KL. Global estimates of occupational accidents. Safety Science. 2006; 44(2):137-56. [DOI:10.1016/j.ssci.2005.08.017]

[24] Habibi E, Soleymanei B, Nateghi R, Lotfirosbehani M, Yarmohammadian M. [Risk management in radiology units of Isfahan University of Medical Sciences' hospitals (Persian)]. Journal of Health Information Managment. 2007; 4(1):133-41. 
[25] Khammar A, PourSadeqiyan M, Marioryad H, Nabi Amjad R, Alimohammadi M, Khandan M. Patient Safety Climate and Its affecting factors among rehabilitation health care staff of Hospitals and Rehabilitation Centers in Iran-Tehran. Iranian Rehabilitation Journal. 2019; 17(1):39-48.

[26] Khandan M, Eyni Z, Ataei Manesh L, Khosravi Z, Biglari H, Koohpaei AR, et al. Relationship between Musculoskeletal Disorders and job performance among nurses and nNursing aides in main educational hospital in Qom Province, 2014. Research Journal of Medical Sciences. 2016; 10(4):307-12.

[27] Afshar S, Mombeyni NN, Hamedi D, Karan SM, Dinari K, Nazarian $\mathrm{M}$. [Job satisfaction and its correlation with motivational power score among occupational therapists in Ahvaz City (Persian)]. Scientific Journal of Rehabilitation Medicine. 2017; 6(1):143-52.

[28] Mastaneh Z, Mouseli L, Zamani M, Boromand E, Dadipoor S, Beizaei $F$, et al. [Investigation of nursing job satisfaction in university hospitals affiliated to Hormozgan University of Medical Sciences (Persian)]. Bimonthly Journal of Hormozgan University of Medical Sciences. 2014; 18(3):260-6.

[29] Azadeh A, Sheikhalishahi M. An efficient taguchi approach for the performance optimization of health, safety, environment and ergonomics in generation companies. Safety and Health at Work. 2015; 6(2):77-84. [DOI:10.1016/j.shaw.2014.11.001] [PMID] [PMCID]

[30] Khandan M, Ataei Manesh L, Eyni Z, Khosravi Z, Biglari $H_{\text {, }}$ Koohpaei AR, et al. Relationship between job content and demographic variables with musculoskeletal disorders among nurses in a University Hospital, Qom Province, 2014. Research Journal of Applied Sciences. 2016; 11(7):547-53.

[31] Firoozi Chahak A, Beheshti M, PourSadeqiyan M. Effect of health, safety, and environment management system training on safety climate in a mine in Yazd Province, Iran. Journal of Occupational Health \& Epidemiology. 2015; 4 (4):198-204 [DOI: 10.3923/rjmsci.2016.307.312] 
This Page Intentionally Left Blank 